\title{
Responsibility as a criterion for determining personal maturity
}

\author{
Abduvali Burkhonov ${ }^{1 *}$, Orif Avlaev $^{2}$, Shoira Abdujalilova ${ }^{1}$, Akram Otaev $^{1}$ \\ ${ }^{1}$ Pedagogy department, Chirchik State Pedagogical Institute of Tashkent province, 111700, \\ Uzbekistan \\ ${ }^{2}$ RTRPP center, Tashkent, Uzbekistan
}

\begin{abstract}
This study was intended testing a new psychodiagnostics tool for diagnosis in order to identify the responsibility recognized by highly qualified professionals as one of the key criteria for maturity in work, especially in agriculture sector. The methodology developed in the framework of this research was conventionally called "The main cause of the VAS situation". The negative correlation between intropunitive attribute and situational responsibility in experiments and the inverse relationship of extrapunitive attribute to the responsibility were also evidence of the responsibility level that can be used to diagnose events, behaviors far from the time they occur. The pertinent results showed that in the impunitive attribute group, non-situational attribution was dominant with $69 \%$, followed by situational attribution with $31 \%$. However, in the extrapunitive attribute group, there was a very different result that was; situational attribution was dominant, accounted for $73 \%$, whereas $27 \%$ of examinees had behavior related to situational attribution. The experiments determined the relationship between extrapunitive, impunitive attributes, and situational responsibility.
\end{abstract}

\section{Introduction}

Responsibility does not have to be overestimated as an individual trait, an important quality that ensures a person's ability to make demands on themselves at work and in life, and its place in society. There are many examples proving that the level of underdevelopment of this quality leads not only to isolated human life, but also to tragic consequences at the state level. On the contrary, life itself shows how high results and courage a person can show in cases of high level of responsibility. In this context, it is possible to understand why researchers, based on vital observations and scientific research, distinguish responsibility as an important criterion of human psychological maturity. In particular, the research of V.P. Pryadein showed that in the period of early adolescence and maturity, the predominance of such qualities as sociocentrism, awareness, results-oriented, internality, satanism, egotism in the structure of responsibility was noted [1,2]. Each of these qualities, which were noted to be related to the quality of responsibility, will be of

\footnotetext{
* Corresponding author: abduvali.burkhonov@yandex.uz
} 
great importance in the formation of maturity. In particular, a person's tendency to evaluate his behavior from a social point of view (sociocentrism), to have a clear idea of the outcome based on conscious motives in each case (awareness, result-oriented), the tendency to search for the causes of events in his life (internality), the predominance of activity-stimulating emotions (satanism) is undoubtedly embodied as important signs of psychological maturity $[1,4]$.

Since responsibility is an important criterion of maturity, it is possible to determine the level of development of this structure by diagnosing it. It is known that in the practice of psychodiagnostics widely used methods developed on the basis of the theory of locus control to check the level of development of a sense of responsibility. This approach is based on the idea that in the type of internal locus control, a person takes responsibility for the events that take place in his life, seeks the causes from him [1, 2]. Indeed, even in specialized scientific research, it has been proven that people with a well-developed sense of responsibility tend to be more internalist in interpreting the behavior not only of themselves but also of others. For example, in the dissertation of N.V. Leifrite, it was proved that the perceptions of a successful person, their integrity, understanding, dynamics, completeness, and rationality were depended on the development level of the quality of responsibility. In particular, the type of responsible person connects a person's success with such qualities as the person's inner resources, responsibility, full realization of their capabilities and abilities in achieving the set goal, finding a way out of difficulties [3-5].

Psychologically, the perfection of a person firmly proves that life itself is multifaceted, characterized by a number of base features. In fact, it is possible to analyze each of these qualities separately and look for measures to test them by psychodiagnostics methods [3, 6]. At the same time, it is believed that it would be effective not only to expand, that is, to identify new important criteria and indicators of maturity, but also to deepen them - to reveal new aspects of some of the criteria already known. It is determined that which aspects, aspects, elements of a quality and trait, which are distinguished as a criterion of perfection, are decisive $[6,8]$. This, no doubt, increases the chances of making the work of psychological diagnosis more subtle and, in itself, more accurately predicting a person's future behavior.

\section{Materials and methods}

The modern psychology confirmed that the possibilities of diagnosing the developmental characteristics of the quality of responsibility in the diagnosis of maturity were much wider. One of the most popular methods widely used in the world to diagnose the level of maturity of the student was the "main cause of the VAS-situation" and a specially developed "NOR-non-situational responsibility questionnaire [6]." The psychological idea of the NOR method is based on the principle of giving the test takers the task of choosing the one that suits them best, out of the two possible answers, by providing incomplete judgments on various life issues. In this case, the issues that lead to some consequences for the sentences presented in the form of incomplete sentences are mentioned. One of the two different outcomes presented to the examinee as an option to end the sentence will be in the context of an imminent, imminent event, and the other is in the context of an event that is not currently dangerous but may occur at some point. According to the theoretical idea based on the methodology, a person with a relatively high level of maturity tends to live much more forward, thinking not only about current needs and problems, but also about the future. In this regard, according to the NOR method, it is 
assumed that people will choose more long-term options [3-5]. To test this hypothesis, the results obtained using the methodology "VAS-the main cause of the situation", i.e., the indicators obtained to determine the level of responsibility and the methodology "NOR-non situational responsibility" were correlated.

The study was conducted using diagnostic tools that have proven their reliability internationally, using complementary research methods that were relevant to the research objectives; selection of institutions from different regions as the object of research; sufficient representativeness of the group of subjects; the obtained empirical values were explained by the fact that they are analyzed using reliable methods of mathematical statistics (Student's t-criterion, correlation analysis by K. Pearson's method). To measure the wide range of groups (teachers, parents, representatives of public organizations, law enforcement officers, those involved in the media, those who want to congratulate themselves and live) in the process of bringing up young people psychologically mature, should try to reflect in other exhibitors. Therefore, the use of a sophisticated psychodiagnostics apparatus that serves to carry out in-depth scientific work in this field is relatively simple to use, but a necessary effort for diagnostic tools that provide compact, rapid tension and processing movements based on tectological requirements $[6,7]$.

The study was intended testing a new psychodiagnostics tool for diagnosis in order to identify a member of the responsibility recognized by highly qualified professionals as one of the key criteria for maturity in work, especially in the field of agriculture. The methodology developed in the framework of this research was conventionally called "The main cause of the VAS situation" and was structured in the form of a closed-ended questionnaire. In the questionnaire, the test taker was asked to think about 10 different life situations and the 3 different reasons that usually lead to them. In this case, the test taker had to determine which of the reasons given with each situation was closer to the truth, the most common in life. As part of this study to test the basic psychometric parameters of the VAS method, empirical tests were conducted with students of higher education institutions. Initially, in order to verify the criterion validity of the method, using this tool, a group of students conducted a critical experiment. Then, based on the recommendation given in scientific sources as a validation criterion [5], the evaluation of specialists-pedagogues who knew students well at the individual level was collected. The values of the relationship between the indicators of the two groups were determined using mathematical and statistical methods, including the method of calculating the r-linear correlation coefficient of K. Pearson [8-10].

\section{Results and discussion}

The results showed that a statistically significant correlation was found between the teachers' assessment of student responsibility and the indicators collected by students on the scale of intropunitive attribution of the methodology "VAS". Furthermore, the relatively high quality of seeing the cause of events in different life situations in their personal and behaviors was also highly valued by experts. At the same time, the expert educators 'assessment of the students` level of responsibility and extrapunitive attribution, that was, a negative correlation between the circumstances or the characteristic of seeing from other persons, the reason for the events taking place, understand responsibility situatively or by someone else`s actions. Accordingly, correlation for Extrapunitive attribution and Intropunitive attribution were 0.57 and 0.45 , respectively (Table 1 ). The presence of a significant correlation between the two series variables was also evident in their visual representation (Figure 1). 
Table 1. The results of correlation analysis of students`sense of responsibility based on psychodiagnostics methodology and expert assessments (On the basis of K.Pearson r-correlation coefficient).

\begin{tabular}{|c|c|c|}
\hline \multirow{2}{*}{$\begin{array}{c}\text { The dominant attribute of } \\
\text { responsibility }\end{array}$} & \multicolumn{2}{|c|}{ Expert assessment of students ' responsibility by teachers } \\
\cline { 2 - 3 } & $\mathrm{r}$ & $\mathrm{p}$ \\
\hline Extrapunitive attribution & $0.57^{* *}$ & $\mathrm{p} \leq 0.01$ \\
\hline Intropunitive attribution & $0.45^{*}$ & $\mathrm{p} \leq 0.05$ \\
\hline
\end{tabular}

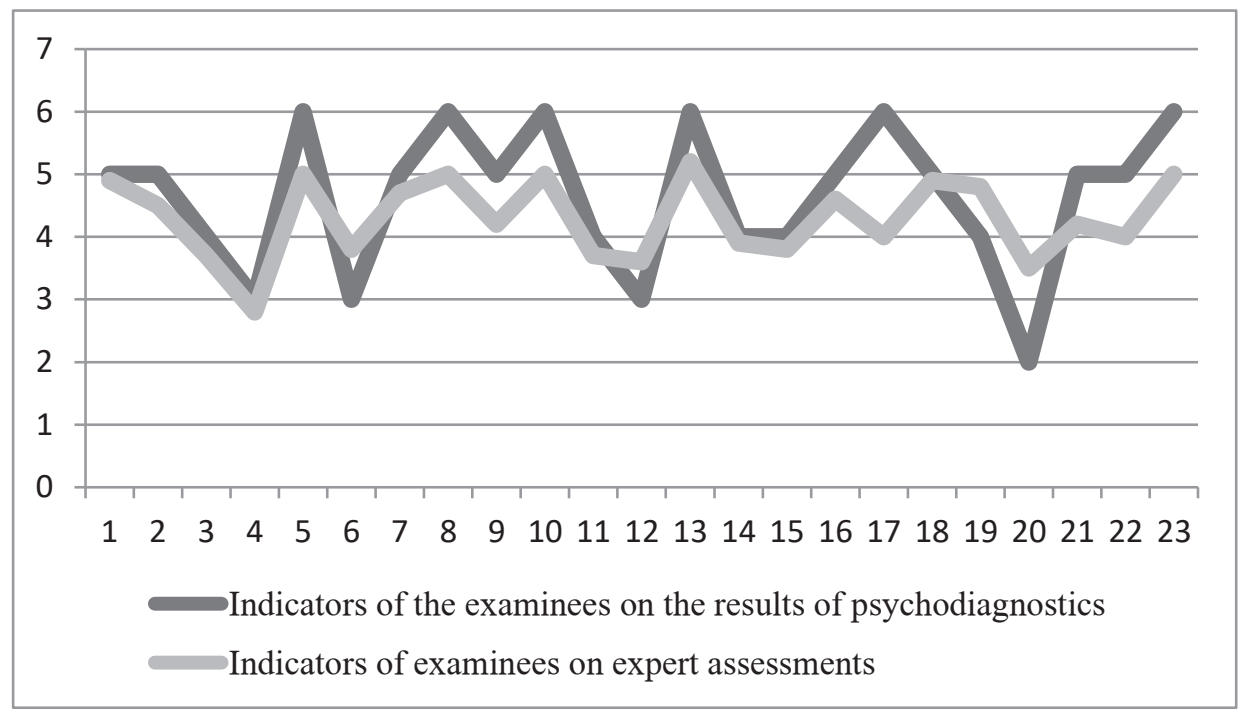

Fig. 1. Results of examination of the quality of the examinee' responsibilities on the basis of psychological diagnostics and expert assessments

It was found that in most cases, the positive assessment of experts with the above positions of indicators of the impunitive attribution scale of the "VAS" methodology was mutually compatible. On the contrary, experts in places where extrapunitive attribution indicators prevail were also giving the student a degree of responsibility. These cases confirmed the existence of a significant link between two variables, namely the indicators obtained as a result of the "VAS" methodology and expert assessments. This in turn proved that the methodology offered was in demand from the point of view of critical validation. A retest examination was conducted with a one-month break to check the degree of reliability of the "VAS" methodology. The statistical relationship between the two stage indicators was investigated on the basis of student' t-criterion, accounted for 0.24 (Table 2).

Table 2. The results of reliability assessment of the method "VAS" using test-retest method (on the t-criterion of Student)

\begin{tabular}{|c|c|c|c|c|}
\hline \multirow{2}{*}{ Research stage } & \multirow{2}{*}{\multicolumn{2}{|c|}{ Statistical indicators }} & \multicolumn{2}{|c|}{ Statistical difference } \\
\hline & & & 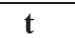 & p \\
\hline \multirow{2}{*}{1} & M1 & 4,6 & \multirow{4}{*}{0.24} & \multirow{4}{*}{$\mathrm{p} \leq 0,05$} \\
\hline & S1 & 1,3 & & \\
\hline \multirow{2}{*}{2} & M2 & 4,5 & & \\
\hline & $\mathrm{S} 2$ & 2,6 & & \\
\hline
\end{tabular}


From the statistical analysis, it was identified that there was no significant discrepancy between the indicators of the retest examination, which confirmed the stability of the results in the time frame and the possibility of obtaining reliable information using the methodology. According to the results of responsibility indicators by test-retest, $26 \%$ students were superior to impunitive attribution, whereas extrapunitive attribution was dominated by $74 \%$ students in the first stage. However, in the second stage, it was lower by $4 \%$ in impunitive attribution, accounted for $22 \%$, and in case of extrapunitive attribution, it was higher by $4 \%$ in the second stage, accounted for $78 \%$ (Figure 2 ).

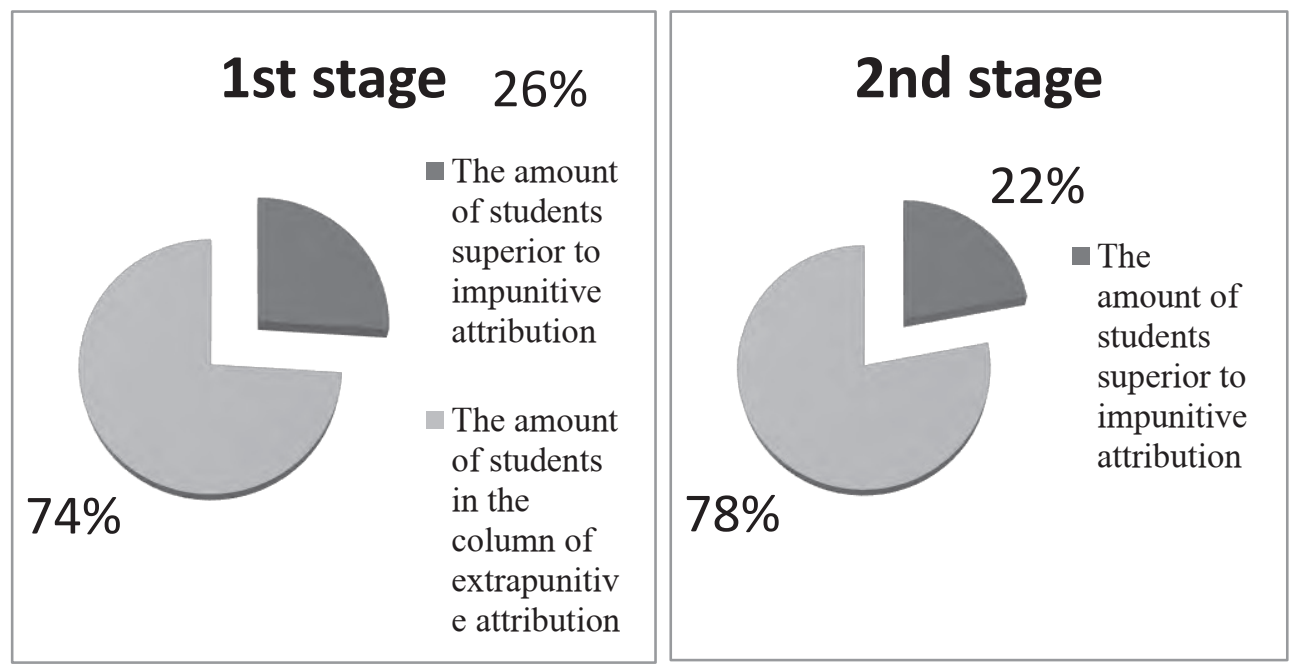

Fig. 2. The results of the comparison of the examinees` responsibility indicators by retest examination.

It can be said that this research work on the development of a simple and mobile methodology from the proportions that serve to check the level of development of the quality of responsible approach in students provides the basis for the following conclusions:

1) two types of attributive reaction-extrapunitive and impunitive attribution on the basis of which there was a greater tendency to evaluate the object of the quality of responsibility in students;

2) there was an opportunity to use the" vas-the main cause of the situation " methodology as a reliable diagnostic tool in forecasting how responsible their students 1 be for different life situations;

3) it was appropriate that the research work in this direction focused on the further examination of other types of validation for the "VAS" methodology, the development of a standard valuation system.

It was planned to focus on one aspect of those indicators, which was important, and was not on the criteria of maturity other than responsibility. From the data presented in the previous sections of the study, it was clear that from an acmelogical point of view, responsibility can be understood as a feature that guarantees the achievement of the expected result without deviating from the quality and timing set at the beginning of the activity. As it was analyzed that the different aspects of that phenomenon, the main attention was drawn to the concept of "historical responsibility" that is often used in the 
social sciences. Historical responsibility is interpreted in a more ethical and political sense, and in general, it is understood that people who make up a particular social group feel responsible for their actions to the future [6]. Researchers note that the level of national self-awareness is assessed by the presence of historical responsibility [7]. Historical responsibility is the extent to which a community or individual has influenced certain events in the history of its peers, the extent to which it is to blame or the cause, and the willingness to take responsibility not only today but in the future for its outcome [6].

The analysis of the correlation indicators showed the positive relationship between impunitive, which was attributive based on an individual's explanation of the cause of their behavior, and non-situational responsibility. Accordingly, it was proven that people, who take responsibility, were tended to act relatively long-term. In other words, it can be argued that among the positive or negative consequences of certain behaviors, a higher level of responsibility would be noted in those ones, who are targeted for situations that are more long-term rather than short-term. At the same time, the above view was supported by the fact that extrapunitive attribute values were inversely related to non-situational responsibility indicators, that was, the ability to look for causes from more external factors and the quality of long-term consequences were negatively correlated.

Table 3. Correlation between impunitive-extrapunitive attribution and non-situational responsibility (based on Ch.Pearson r-correlation coefficient)

\begin{tabular}{|c|c|c|}
\hline Attribute directions & Situational responsibility & $\begin{array}{c}\text { Non-situational } \\
\text { reponsibility }\end{array}$ \\
\hline Impunitive attribute & $-0.48^{*}$ & $0.63^{* *}$ \\
\hline Extrapunitive attribute & $0.61^{* *}$ & $-0.59^{* *}$ \\
\hline
\end{tabular}

Note: $* p \leq 0.05$ level statistical significance; $* * p \leq 0.01$ level statistical significance

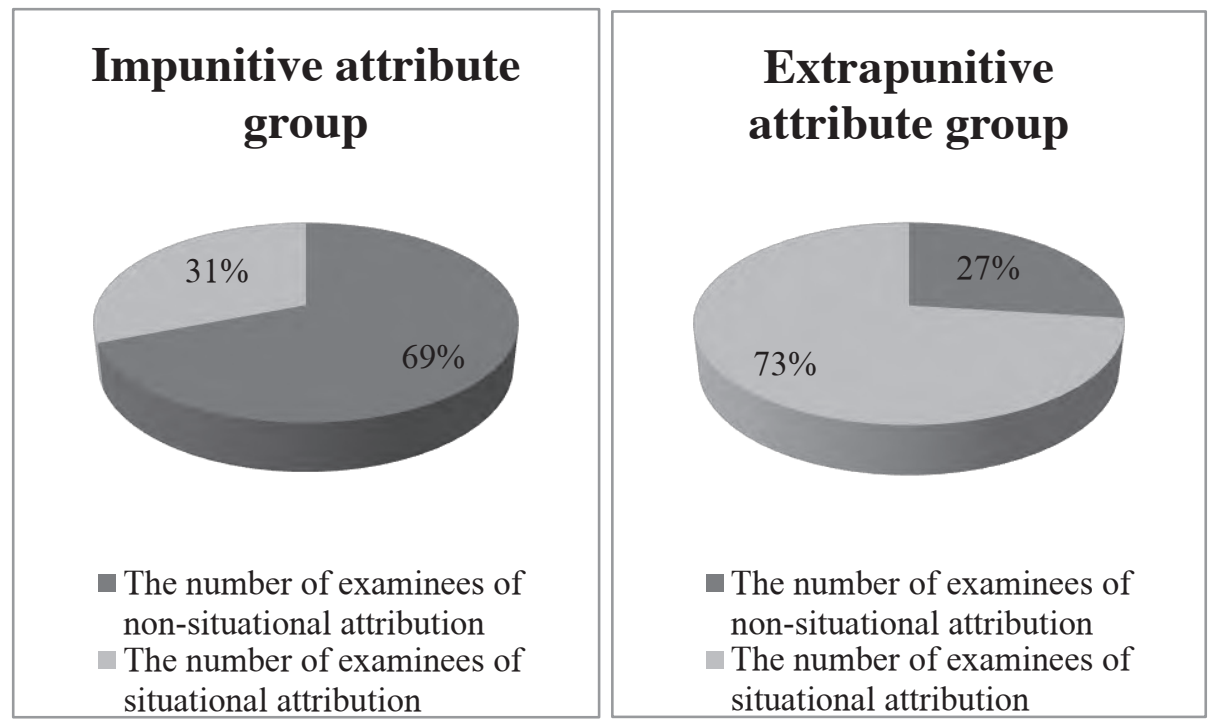

Fig. 3. Distribution of examinees with different leading attributes according to the indicator of responsibility 
Similarly, a negative correlation between impunitive attribution and situative responsibility can be noted, and the inverse association of extrapunitive attribution with non-communicative responsibility also proved that it was possible to diagnose the degree of responsibility of events, behavior arbitrators on the basis of an indicator of attention to the results of different degrees of time away from the time they occur. It was found that in the groups of examinees who dominated the two opposite types of attribution, there was a slight discrepancy in the ratio of the indicators of non-communicative responsibility. The pertinent results showed that in the impunitive attribute group, non-situational attribution was dominant with $69 \%$, followed by situational attribution with $31 \%$. However, in the extrapunitive attribute group, there was a very different result that was; situational attribution was dominant, accounted for $73 \%$, whereas $27 \%$ of examinees had behavior related to situational attribution. Overall, it can be said that impunitive attribution among the superior examiners was the contingent majority of those who give preference to views that imply unequivocal responsibility. On the contrary, in this regard, the incidence of those, who were superior to the quality of extrapunitive attribution in the group of target recipients in situational responsible situations, was greater than the proportion. In fact, there was a remarkable interaction between two series of variables.

\section{Conclusion}

In a situation, where there is a tendency to take more responsibility and look for reasons and factors in oneself, there is usually a tendency to pay more attention to the long-term consequences of events. Furthermore, indicators of non-situational responsibility were a sign of how well a person could understand the consequences of their actions, and its high levels could be taken as an important sign of maturity. One of the components of a person's maturity is his or her responsibility. The negative correlation between inpunitive attribute and situational responsibility in experiments and the inverse relationship of extrapunitive attribute to non-situational responsibility also suggest that events can be diagnosed on the basis of the degree to which they are focused on the consequences of different levels of behavior. In the groups of subjects who dominated the two opposite attribute types, there was also a marked difference in the ratio of non-situational responsibility.

Evidently, the tools currently offered to academic practitioners to diagnose the level of personal responsibility are, on the one hand, well-grounded, have long been used effectively abroad, and, on the other hand, complicate everyday pedagogical and psychological needs. It is worth noting that most of them require knowledge and are designed for older test takers. In addition, this methodology is in the form of a direct questionnaire, which in all cases encourages the subject to think about the criticism of blaming someone or something for an event (in other words, blaming someone or a situation) or looking for a reason. In such a situation, it is necessary to take into account that the subjects are strongly influenced by a high level of social approval motivation ("facade effect") and are more likely to respond unfairly. An internal guiding mechanism of consciousness, activity, and self-awareness is important in the development of a person Because his development as a person is determined by his interests, character, abilities, mental development, needs, labor activity. When these qualities develop and his attitude to social life, people, society reaches a certain stage, he rises to the level of maturity. 


\section{References}

1. A. M. Rikel, RUDN Journal of Psychology and Pedagogics 17, 3 (2020)

2. B. Domańska-Szaruga, Entrepreneurship and Sustainability Issues 7, 3 (2020)

3. O. U. Avlaev, Sh. A. Abdujalilova, International Journal of Psychosocial Rehabilitation 24, 06 (2020)

4. O. U. Avlaev, A. A. Burkhanov, D. M. Ismoilova, M. A. Norkuzieva, TEST enginering \& management, 214 (2020)

5. U. A. Butaeva, O. U. Avlaev, N. Abdumannotova, Journal of critical reviews 7, 12 (2020)

6. E. Yu. Vostretsov, I. A. Simonova, Pedagogical education in Russia, 5 (2015)

7. U. P. Kosova, Humanities 2, 20 (2012)

8. J. C. De Winter, Practical Assessment, Research, and Evaluation 18(1), 10 (2013)

9. S. Bal-Taştan, S. M. M. Davoudi, A. R. Masalimova, A. S. Bersanov, R. A. Kurbanov, A. V. Boiarchuk, A. A. Pavlushin, EURASIA Journal of Mathematics, Science and Technology Education 14(6), 2353-2366 (2018)

10. A. Salim, T. Tawali, S. Sudirman, JUPE: Jurnal Pendidikan Mandala 5(6), 11 (2020) 